\title{
A expressão da pluracionalidade em libras
}

\author{
Luciana Sanchez-Mendes \\ Universidade Federal Fluminense (UFF), Niterói, Rio de Janeiro, Brasil \\ sanchez.mendes@gmail.com \\ André Nogueira Xavier \\ Universidade Federal do Paraná (UFPR), Curitiba, Paraná, Brasil \\ andre.xavier.br@gmail.com
}

DOI: http://dx.doi.org/10.21165/el.v45i1.633

\section{Resumo}

Este artigo descreve o comportamento semântico da duplicação de mão em verbos tipicamente produzidos com uma mão na Língua Brasileira de Sinais (libras). Defendemos que a duplicação de mãos nesses sinais expressa pluracionalidade e argumentamos que um traço que determina a leitura dos verbos pluracionalizados na libras é a direcionalidade.

Palavras-chave: libras; semântica verbal; pluracionalidade; direcionalidade.

\section{The Expression of Pluractionality in Brazilian Sign Language (libras)}

\begin{abstract}
This paper describes the semantic behavior of hand duplication in verbs that are typically produced with one hand in Brazilian Sign Language (libras). It is claimed that hand duplication in these signs expresses pluractionality, and it is argued that one feature that determines the readings associated with pluractionalized verbs is directionality.
\end{abstract}

Keywords: libras; verbal semantics; pluractionality; directionality.

\section{Introdução}

O objetivo deste artigo é discutir qual a contribuição semântica da duplicação de mãos em alguns sinais da Língua Brasileira de Sinais (libras). A libras é uma língua legitimada como meio de comunicação e expressão da comunidade surda no território brasileiro, reconhecida pela lei $\mathrm{n}^{\mathrm{o}} 10.436$ de 24 de abril de 2002 e regulamentada por meio do decreto 5626/2005. Desde o decreto de 2005, as universidades têm tentado atender à exigência de inclusão do ensino de libras como disciplina curricular em todos os cursos de licenciatura e fonoaudiologia. Nesse sentido, houve um aumento, na última década, do interesse pelos estudos sobre essa língua, pelo menos no espaço acadêmico. No entanto, ainda há muitos aspectos da língua a serem descritos.

Um dos objetivos deste trabalho é contribuir para o entendimento da semântica da libras, ainda muito pouco explorada nas pesquisas atuais. A hipótese que vamos defender é a de que a duplicação no número de mãos em alguns sinais da libras que são tipicamente produzidos com uma mão expressa pluracionalidade, um fenômeno semântico atestado em uma variedade de línguas não indo-europeias, como se verá neste artigo. 
Este artigo está dividido da seguinte forma: a seção 2, a seguir, apresenta a origem dos dados utilizados neste trabalho; a seção 3 discute, a partir de uma perspectiva semântica, o fenômeno da pluracionalidade em outras línguas em que foi estudado; a seção 4 apresenta uma proposta para os dados da libras; e a seção 5 apresenta, por fim, as considerações finais e os próximos passos da pesquisa.

\section{Origem dos Dados}

Xavier (2014) descreve e analisa sinais da libras que, apesar de canonicamente serem articulados com uma mão, são, em alguns contextos, realizados com duas. O autor designa esse processo como duplicação, o qual, segundo ele, pode acontecer na libras por fatores estritamente fonético-fonológicos, ou por fatores de natureza semântica. Entre os primeiros, Xavier identificou tanto casos de variação livre quanto de variação motivada pelo ambiente fonológico - caso chamado pelo autor de 'coarticulação'. Entre os últimos, ele observou casos de expressão de pluralidade, aspecto e intensidade.

Os dados reanalisados e discutidos neste trabalho consistem de 14 dos 22 sinais coletados por Xavier (2014) e tratados pelo mesmo autor como casos em que a duplicação de mãos se dá por fatores semânticos. Como critério de seleção, adotamos a categoria gramatical dos sinais, restringindo-nos aos verbos listados em (01).

(01) ACUSAR, AVISAR, BEIJAR, IGNORAR, PAGAR, VER APRENDER, COLAR, COMER, ENTENDER, IMAGINAR, INVENTAR, IR-EMBORA, RIR ${ }^{1}$.

Embora, conforme mostra Rodero-Takahira (2015), o estabelecimento da categoria gramatical dos sinais da libras seja uma tarefa difícil e que ainda precise de mais investigações, tratamos os sinais em (01) como verbos por indicarem eventos ou estados. Mais investigações serão necessárias para que sejam apresentados critérios formais (morfológicos e sintáticos) que permitam ratificar essa análise.

Excluímos, portanto, casos cuja categoria gramatical não nos pareceu clara (CAFÉ, OPINIÃO, O-QUÊ, MAGR@, DIFERENTE), bem como casos que, pela semântica, não nos pareceram pertencer à categoria dos verbos (ÁRVORE, DINHEIRO) $)^{2}$.

Como exemplo dos sinais selecionados para este trabalho, tomemos BEIJAR e IR-EMBORA. Tanto em BEIJAR (figura 1), quanto em IR-EMBORA (figura 2), a versão bimanual é empregada para expressar pluralidade. A diferença, no entanto, é que no primeiro caso a duplicação indica pluralidade do complemento do verbo e, no segundo, do evento expresso por ele. Precisamente, a versão monomanual de BEIJAR, feita com a mão configurada de tal forma que os dedos se tocam pelas pontas, é

\footnotetext{
1 Seguimos aqui as convenções de Felipe de Souza (1998), de acordo com as quais os sinais são glosados em caixa alta e verbos, por ausência de marcas flexionais de tempo e pessoa, no infinitivo. Além disso, sinais traduzidos por mais de uma palavra do português apresentam essas palavras hifenizadas.

2 É importante dizer que o objetivo principal das glosas é oferecer uma tradução do sinal para o português. Nesse sentido, a categoria gramatical da palavra em português não deve ser entendida como sendo necessariamente também a categoria gramatical do sinal da libras. CAFÉ ilustra bem essa questão uma vez que o sinal glosado com essa palavra do português, a depender do contexto de uso, pode significar o nome (café) ou uma ação relacionada a ele (tomar café).
} 
empregada em contextos em que o sinalizante se despede mandando beijos para uma única pessoa, enquanto sua versão bimanual é utilizada quando essa ação é dirigida a mais de uma. No caso de IR-EMBORA, a versão monomanual, realizada por meio de um movimento para frente durante o qual os dedos polegar e indicador, inicialmente separados (enquanto os demais estão fechados), se aproximam e passam a se tocar pelas pontas, é empregada para fazer referência a um evento de ir embora, ao passo que sua versão bimanual é usada quando se quer fazer referência a vários desse mesmo evento.

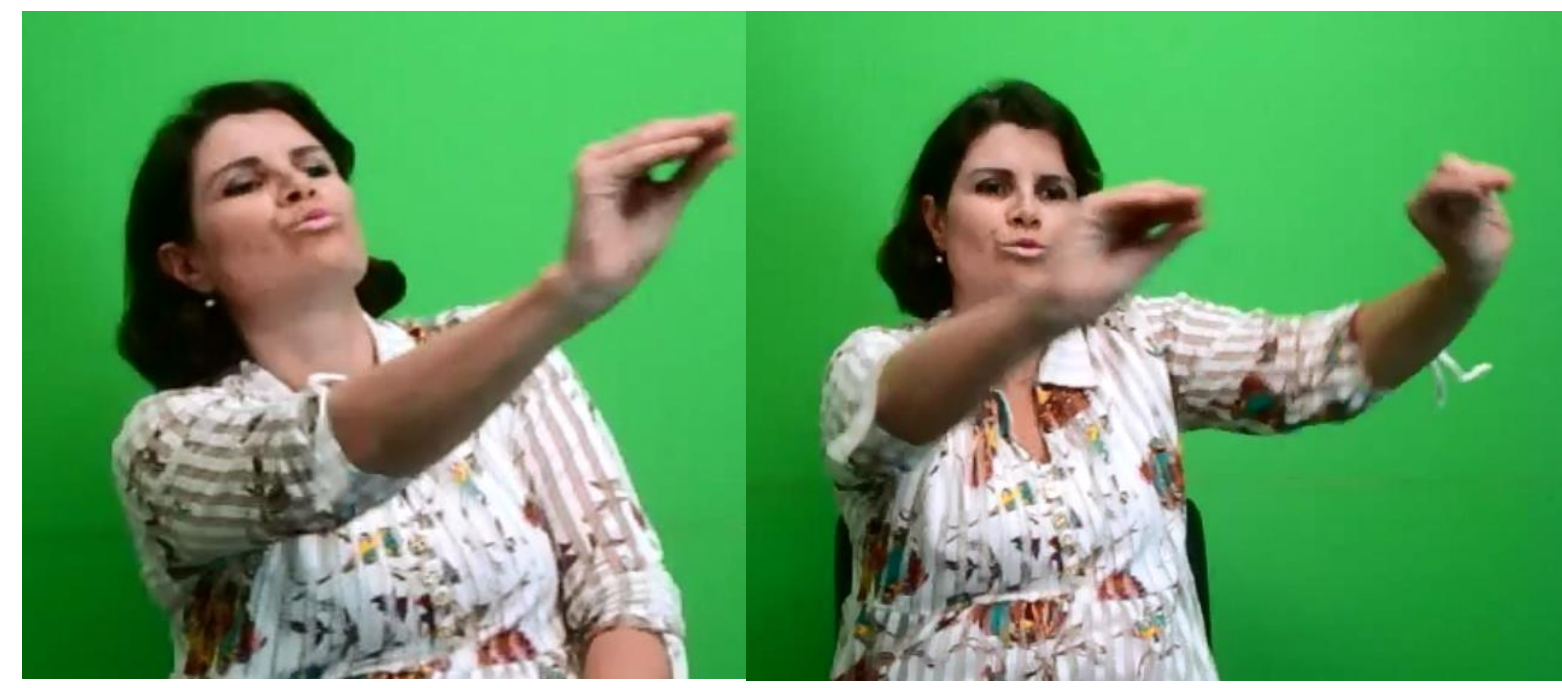

Despedir-se de uma pessoa (com beijos).

Despedir-se de várias pessoas (com beijos).

Figura 1. BEIJAR ${ }^{3}$

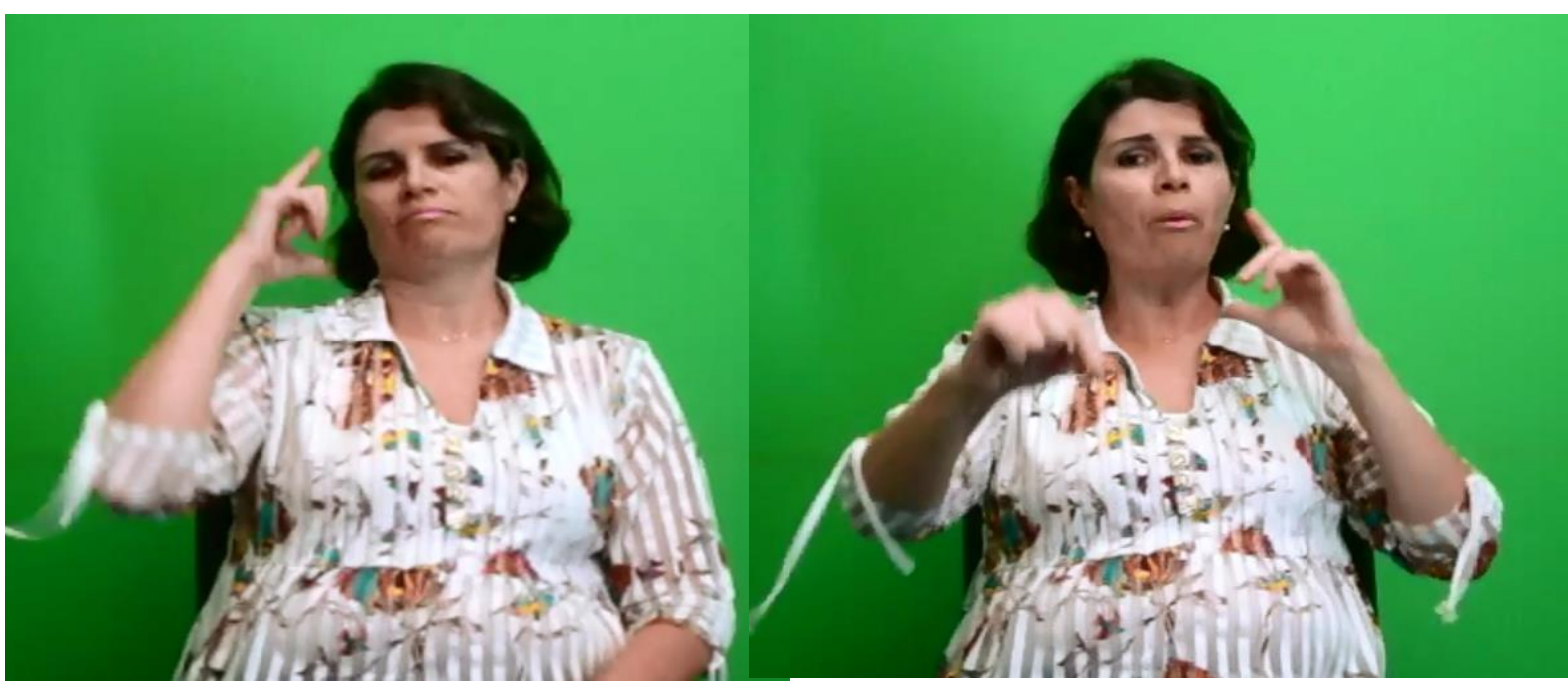

Uma pessoa vai embora.

Várias pessoas vão embora (uma atrás da outra)

Figura 2. IR-EMBORA

3 Agradecemos à surda Regiane Pinheiro Agrella por muito gentilmente permitir que sua imagem fosse usada para ilustrar os dados em discussão. 
A hipótese que vamos defender neste artigo é a de que as duas noções de pluralidade ilustradas acima são abarcadas pela operação de pluracionalidade, que ocorre em uma variedade de línguas tipologicamente muito diversas. A próxima seção discute a ocorrência da pluracionalidade em outras línguas, bem como apresenta o modo como ela tem sido analisada pela teoria semântica.

\section{Pluracionalidade}

A pluracionalidade é entendida, de forma geral, como a marcação de plural nos verbos que não se confunde com morfemas de concordância. Nas línguas indoeuropeias, estamos habituados à marcação de plural no verbo apenas para marcar concordância com uma pessoa plural. Dessa forma, no exemplo abaixo do português, a diferença de número singular e plural no verbo indica variação do número do sujeito.

$$
\begin{array}{lll}
\text { a. Comi. } & \text { PORTUGUÊS } \\
\text { b. Comemos. } &
\end{array}
$$

Outras línguas, porém, possuem morfemas que não marcam mera concordância com o argumento do verbo, mas podem expressar além de uma pluralidade de argumentos, outras leituras, tais como intensidade e plural de eventos. Esse tipo de morfema tem sido tratado na literatura como marcador pluracional ou morfema de pluracionalidade. A pluracionalidade é uma operação encontrada em muitas línguas do mundo, especialmente nas línguas não indo-europeias. Ela é normalmente expressa por uma reduplicação do verbo, mas também pode ter a forma de afixos ou mesmo de supleção da raiz.

Apresentamos abaixo exemplos de línguas tipologicamente distintas em que a pluracionalidade tem efeitos semelhantes aos atestados para a duplicação de mãos em alguns verbos da libras, como veremos no decorrer do artigo. Em Kaingang (Macro-Jê, Brasil $)^{4}$, por exemplo, a duplicação do verbo indica uma pluralização dos argumentos, conforme ilustrado abaixo.

$$
\begin{array}{ll}
\text { a. } & \text { hadn } \\
\text { b. } & \text { agitar uma camisa' } \\
\text { hadnhadn } \\
\text { 'agitar muitas camisas' }
\end{array}
$$

KAINGANG

Em Karitiana (Tupi/Arikén, Brasil), por sua vez, a duplicação da raiz verbal está sempre associada a uma pluralização dos eventos com distribuição no tempo.

$$
\begin{array}{lll}
\text { a. } & \text { João } & \text { i-'ot- } \varnothing . \\
& \text { João } & \text { PART-cair-ABS }
\end{array}
$$

KARITIANA

'O João caiu.'

4 Estamos seguindo a Convenção para Grafia dos Nomes Tribais da Associação Brasileira de Antropologia (ABA) estabelecida em 14 de novembro de 1953 que recomenda a grafia dos nomes das línguas e famílias de línguas indígenas brasileiras com a primeira letra maiúscula.

5 Abreviaturas utilizadas no dado do Karitiana: ABS = absolutivo; DUPL = duplicação; PART = particípio. 
b. João i-'ot-'ot- $\varnothing$.

João PART-cair-DUPL-ABS

'O João caiu (mais de uma vez).

(SANCHEZ-MENDES, MÜLLER, 2007)

Já em nahuatl (uto-asteca, México), a pluracionalidade é marcada pela repetição da primeira sillaba do verbo e expressa intensidade.

(05) a. tlania

NAHUATL

'perguntar'

b. tlatlania

'perguntar insistentemente'

(GARIBY, 1961 apud CUSIC, 1981)

Essa variabilidade de leituras dos marcadores pluracionais nem sempre é totalmente livre. Em algumas línguas, é possível determinar o tipo de leitura que a sentença terá de acordo com o tipo de verbo que recebeu o marcador pluracional. Em checheno (caucasiana, Chechênia), as classes verbais determinam o tipo de leitura que as sentenças pluracionais possuem. Mais especificamente, a distinção télico-atélico tem um papel importante na determinação do significado dos verbos com marcador pluracional (YU, 2003).

A telicidade é uma propriedade associada à acionalidade dos predicados verbais (também conhecida como aspecto lexical). Ela foi difundida a partir do artigo seminal do filósofo americano Zeno Vendler (VENDLER, 1957). Vendler (1957) não utiliza propriamente o termo telicidade, mas define a propriedade em termos de clímax ou término lógico. Predicados télicos são os que possuem um fim previsto, determinado (do grego telos, 'fim'). Por exemplo, o sintagma desenhar um círculo tem um ponto final natural descrito pelo predicado associado ao seu objeto e é, portanto, télico. Correr, por sua vez, é um predicado atélico porque não tem um fim determinado pelo léxico do verbo. Por conta disso, faz sentido dizer terminar de desenhar um círculo, mas não terminar de correr.

Em checheno, predicados télicos têm leitura de plural de eventos quando os verbos recebem o morfema pluracional, enquanto predicados atélicos têm leitura durativa. A pluracionalidade não é expressa por reduplicação na língua, mas por meio de uma alternância vocálica na raiz verbal. No exemplo abaixo, o predicado verbal télico qwessira 'atirar', quando é pluracionalizado, tem a forma qissira e uma leitura de pluralidade de eventos.

$$
\begin{array}{lll}
\text { a. } & \text { as } & \text { q'iigashna } \\
& \text { eu corvo.PL.DAT }
\end{array}
$$

twop-qwessira.

CHECHENO

'Eu atirei nos corvos.'

\footnotetext{
6 Um parecerista anônimo, a quem agradecemos, nos chamou a atenção para o fato de que a leitura de intensidade poderia ser uma consequência da pluralização de eventos. Assim, 'perguntar muitas vezes' teria um efeito de 'perguntar insistentemente'. Nós não temos acesso às sutilezas semânticas da pluracionalidade em nahuatl, portanto, não podemos afirmar que seja esse o caso.

7 Yu (2003) não apresenta o significado das abreviaturas utilizadas nas glosas.
} 


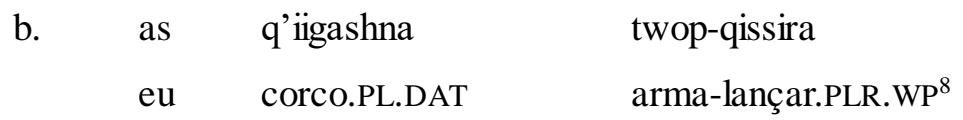

'Eu atirei nos corvos muitas vezes.'

(YU, 2003)

Predicados atélicos, por outro lado, têm leitura durativa e não de plural de eventos quando recebem morfemas pluracionais em checheno. $\mathrm{O}$ exemplo abaixo com o verbo xoizhira 'doer' pluracionalizado como xiizhira ilustra essas propriedades.
a. Cyna
chow xoizhira.
3SG.POSS
ferida doer.WP
'Sua ferida doeu momentaneamente.'
b. Cyna chow xiizhir.
3SG.POSS ferida doer.PLR.WP

CHECHENO

'Sua ferida doeu por muito tempo.'

(YU, 2003)

Como se vê, há muitos efeitos semânticos atribuídos à pluracionalidade. O trabalho pioneiro de Cusic (1981) reuniu uma grande quantidade de dados em diversas línguas e averiguou que a diversidade de leituras atestadas pode ser capturada por quatro parâmetros básicos. $\mathrm{O}$ primeiro diz respeito à diferença entre repetição de fase e a repetição de evento. A repetição de evento ocorre quando um verbo pluralizado denota uma repetição de eventos do mesmo tipo denotado pelo verbo. Assim, nos exemplos do checheno, o verbo para 'atirar' quando pluralizado denota um plural de eventos de atirar. A repetição de fase, por sua vez, ocorre quando um verbo denota uma pluralidade de subeventos ou fases internas que são de natureza diferente do evento denotado pelo verbo em si. Por exemplo, mordiscar, em português, é um verbo que denota fases de dar pequenas mordidas. Ou seja, mordiscar denota um plural de subeventos de morder e não de mordiscar.

Em Emerillon (Tupi/Tupi-Guarani, Brasil), a diferença entre repetição de fase e de evento é expressa por manismos morfológicos distintos: a reduplicação monossilábica e a reduplicação dissilábica (ROSE, 2005). Os exemplos abaixo ilustram essa propriedade. Em (08a) a reduplicação monossilábica indica uma repetição de fase, o processo de roer é resultado de várias fases do evento morder. Já em (08b), a reduplicação dissilábica indica repetição do evento de sair ${ }^{9}$.
a. $\quad$ ãdud $\mathrm{A}_{\mathrm{a}}$
W la o- $[\mathrm{su}] \mathrm{su} \& \mathrm{u}$.
rato madeira3-RED-morder ${ }^{10}$
'O rato roeu a madeira.'
b. [õhm (D) õ-hem-ne
o- 2 a.

EMERILLON

\footnotetext{
8 Como se pode notar, cada autor apresenta uma glosa diferente para o morfema pluracional. Yu (2003) prefere utilizar a abreviatura PLR. O autor não apresenta o significado das outras abreviações utilizadas. 9 Agradecemos ao parecerista anônimo que indicou a bibliografia com a existência de línguas que expressam a repetição de fase e de evento com estratégias diferentes.

10 Abreviaturas utilizadas no dado do Emerillon: $3=$ terceira pessoa; RED = reduplicação; CONTRAST $=$ contrastivo.
} 
O segundo parâmetro está ligado às diversas leituras proporcionadas pelos marcadores pluracionais quanto ao grau de intensidade da ação. Os casos mais comuns são os de intensidade, como o caso do nahuatl apresentado acima em que a versão pluracionalizada do verbo correspondente a 'perguntar' expressa perguntar insistentemente. No entanto, a pluracionalidade também pode expressar diminuição do grau de intensidade da ação, como é o caso do dialeto sierra nahuat da língua nahuatl em que koči.sneki significa 'querer dormir' e ko.koči.sneki expressa 'continuamente querer dar pequenos cochilos' (KEY, 1960, p. 131).

O terceiro parâmetro descrito em Cusic (1981) é o da conectividade e está ligado ao grau de contiguidade das repetições. Esse parâmetro é ilustrado com o exemplo apresentado acima em checheno em que o verbo atélico que significa 'doer' expressa tal noção somada à noção de duração por muito tempo quando pluracionalizado. $\mathrm{O}$ quarto parâmetro é o da distributividade e está ligado à distribuição no tempo, no espaço ou sobre os participantes dos eventos repetidos. Um exemplo desse tipo de leitura é o caso do Karitiana, em que a pluracionalidade sempre está associada a uma distribuição dos eventos no tempo.

A proposta de Cusic (1981) de quatro parâmetros tem um grande potencial descritivo que pode auxiliar no estudo de novas línguas, embora não tenha um poder explicativo do mesmo aporte (YU, 2003). Em um trabalho mais recente, Lasersohn (1995) busca uma unificação para as noções discutidas em Cusic (1981) e afirma que a pluracionalidade tem uma semântica básica de plural. Segundo essa proposta, uma sentença com verbo pluracional será verdadeira para um grupo de eventos se o correspondente singular deste verbo for verdadeiro para cada evento individual do grupo, conforme expressa a forma lógica em (09).

$$
\mathrm{V}-\mathrm{PA}(\mathrm{X}) \Leftrightarrow \forall e \in \mathrm{X}[\mathrm{V}(e)] \& \operatorname{card}(\mathrm{X}) \geq \mathrm{n}
$$

(LASERSOHN, 1995, p. 121)

Em palavras: A combinação do verbo com o marcador pluracional V-PA se aplica a um grupo de eventos $\mathbf{X}$ se, e somente se, para todo evento e que pertence a esse grupo de eventos $\mathbf{X}$, e é um evento denotado pelo verbo $\mathbf{V}$ e a cardinalidade do grupo de eventos $\mathbf{X}$ é maior ou igual a um número $\mathbf{n}$ pragmaticamente determinado que garante que $\mathbf{X}$ não seja preenchido por 1 ou vazio.

Além dessa informação básica de plural, o marcador pluracional pode ter uma informação adicional de como os eventos pluralizados estão dispostos, se continuamente, se distribuídos no tempo, no espaço ou sobre os participantes. Dessa forma, a proposta consegue abarcar as noções de intensidade, continuidade e distribuição no tempo, espaço e participantes com uma análise unificada com base na semântica de plural. A proposta básica de pluracionalidade com base em uma operação semântica de plural de eventos vem sendo empregada na investigação recente da pluracionalidade em várias línguas com diferenças nos detalhes das análises. Ver, por exemplo, a análise de Yu (2003) para o checheno e de Sanchez-Mendes e Müller (2007) para o Karitiana.

Uma vez apresentadas as propriedades dos marcadores pluracionais nas línguas orais, bem como sua análise mais comum, apresentaremos na próxima seção a nossa 
proposta para os dados de verbos com duplicação de mãos na libras.

\section{Proposta}

O objetivo desta seção é apresentar e defender a proposta de que a duplicação no número de mãos em alguns verbos da libras que são tipicamente produzidos com uma mão expressa pluracionalidade. Conforme apresentado anteriormente, pelo menos as interpretações de plural de argumentos e de plural de eventos estão presentes nesses dados. Conforme será discutido mais abaixo, a leitura de intensidade também é encontrada em dados desse tipo. Precisamente, nossa proposta será, então, a de que todos esses efeitos de interpretação podem ser explicados pela operação semântica de pluracionalidade levando em conta os parâmetros de intensidade (segundo parâmetro) e de distribuição sobre participantes e no tempo (quarto parâmetro).

A seção anterior mostrou que, em algumas línguas, a classificação verbal segundo a telicidade pode determinar os tipos de leituras encontrados nos verbos pluracionais. Trabalhos recentes acerca das línguas de sinais têm mostrado que essas línguas não apenas codificam a distinção télico-atélico, ou seja, apresentam propriedades gramaticais associadas a essa distinção, mas expressam a telicidade de uma forma mais acessível universalmente por meio de gestos salientes (cf., por exemplo, Wilbur (2003), Malaia e Wilbur (2012), Strickland et al. (2015)). Entretanto, não é possível afirmar categoricamente que a distinção télico-atélico tem um papel na gramática da libras ${ }^{11}$.

Por outro lado, é possível observar que a seleção de leituras dos verbos pluracionalizados pode ser determinada por um outro tipo de classificação verbal: a direcionalidade. A direcionalidade é um aspecto bastante estudado das línguas de sinais e divide os verbos em direcionais e não direcionais ${ }^{12}$. Os verbos direcionais são aqueles cuja forma varia de acordo com a localização no espaço de sinalização dos participantes a que seus argumentos fazem referência ${ }^{13}$. Verbos não direcionais, por sua vez, são invariáveis segundo essa propriedade. Como se pode observar no quadro (1) a seguir, dos 14 verbos selecionados para este trabalho, seis são direcionais e oito não direcionais.

\footnotetext{
11 É preciso destacar que Finau (2004) faz uma descrição das noções de tempo e aspecto em libras. No entanto, uma vez que autora lança mão de noções sintáticas, semânticas e pragmáticas em sua análise, não é possível averiguar se a telicidade tem um papel na classificação dos predicados verbais de um ponto de vista lexical, como pretende Vendler (1957).

12 Esses verbos recebem também o nome de verbos de concordância em alguns trabalhos (QUADROS; KARNOPP, 2004). Uma vez que não queremos nos comprometer com análises desse tipo, tendo em vista trabalhos como o de Moreira (2007), utilizamos a terminologia direcionalidade, mais neutra acerca da função desse traço.

13 Quando se faz referência a participantes não presentes ou cuja localização não pode ser traçada no espaço imediato, o sinalizante thes atribui uma localização no espaço em frente a seu corpo à sua direita ou esquerda (MOREIRA, 2007).
} 


\begin{tabular}{|c|c|}
\hline \multicolumn{2}{|c|}{ Quadro 1. Dados } \\
\hline Verbos direcionais & Verbos não direcionais \\
\hline $\begin{array}{c}\text { ACUSAR, AVISAR, BEIJAR, IGNORAR, } \\
\text { PAGAR, VER. }\end{array}$ & $\begin{array}{l}\text { APRENDER, COLAR, COMER, ENTENDER, } \\
\text { IMAGINAR, INVENTAR, IR-EMBORA, RIR. }\end{array}$ \\
\hline
\end{tabular}

Observamos que, pelo menos nos dados aqui considerados, a forma bimanual de verbos direcionais sempre apresenta uma leitura de pluralidade de argumentos. Isso pode ser observado, por exemplo, com o sinal BEIJAR, apresentado anteriormente na figura 1, empregado, por exemplo, em despedidas. Como se viu nesse caso, a forma monomanual é usada quando se despede de uma pessoa (se beija), ao passo que a forma bimanual é empregada quando se despede de mais de uma pessoa (se beijam). O mesmo acontece com AVISAR que, como ilustrado na figura 3, é realizado com duas mãos quando seu complemento ou seu sujeito fazem referência a mais de uma entidade. Precisamente, a versão monomanual de AVISAR, realizado com a mão configurada de tal forma que apenas o polegar e o dedo mínimo aparecem distendidos, é empregada quando tanto seu sujeito quanto seu complemento são singulares. Já a versão bimanual é empregada quando ou o complemento ou o sujeito é plural ${ }^{14}$.

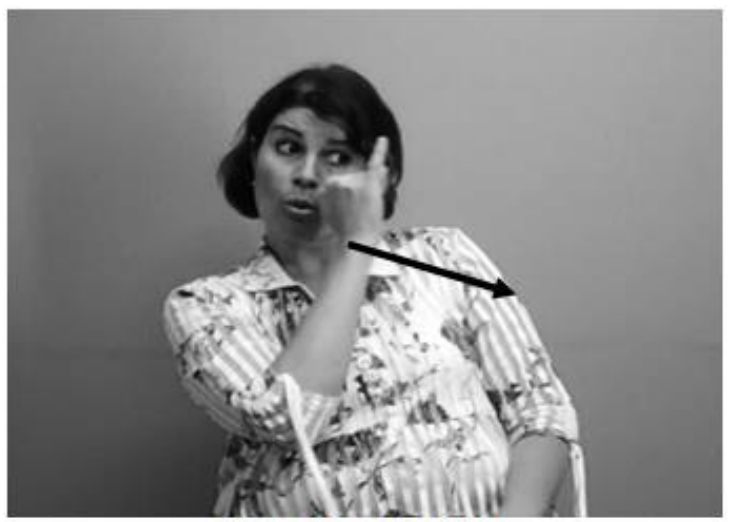

Eu o(a) aviso(ei)

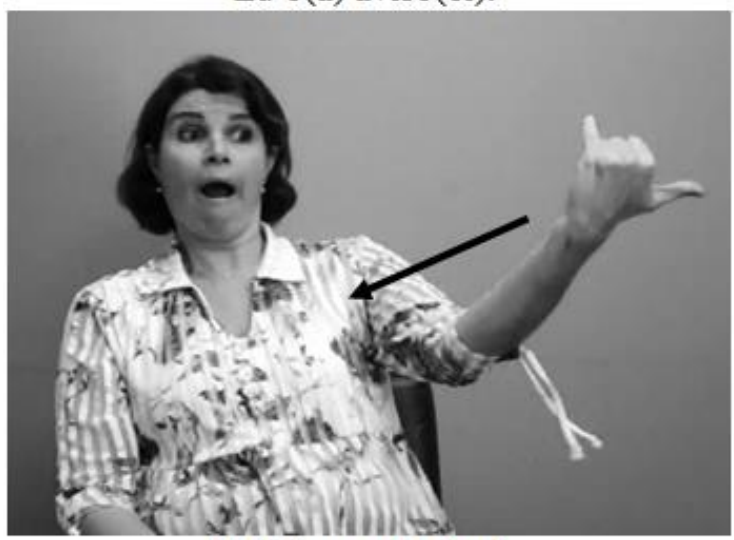

Ele(a) me avisa(ou).

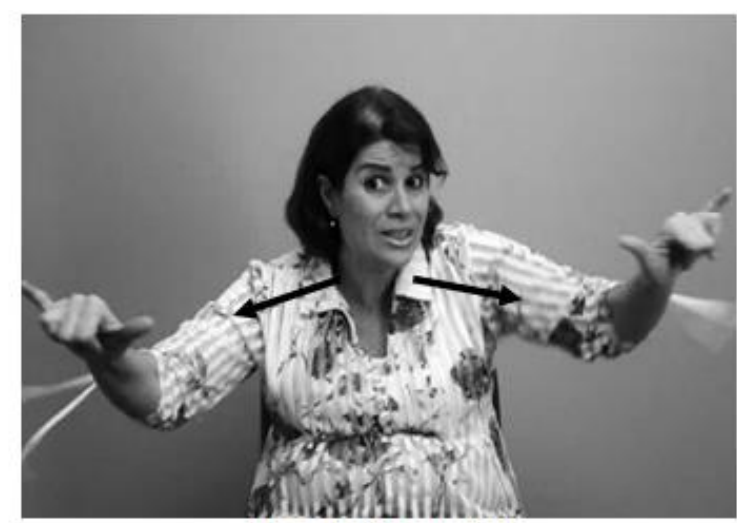

Eu os(as) aviso(ei)

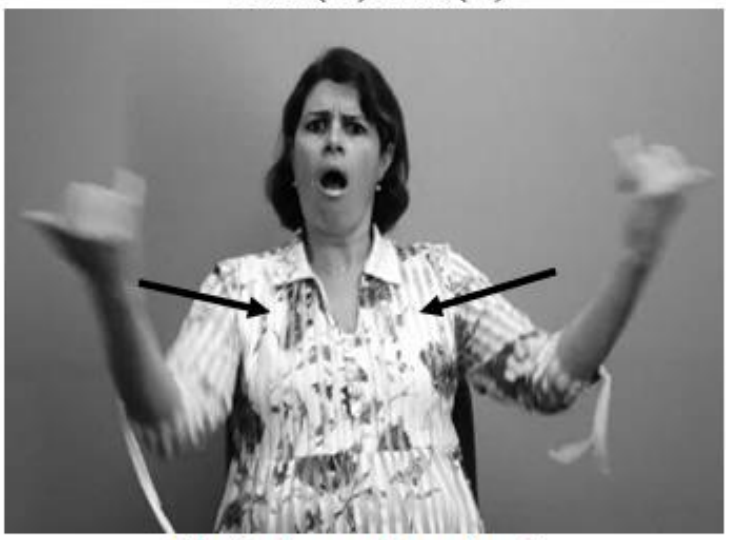

Eles(as) me avisam(ram).

Figura 3. AVISAR

14 Xavier (2014) documenta que parece haver restrições em relação à distribuição dessas formas. A forma bimanual para expressar plural de complemento só ocorre se o sujeito for uma primeira pessoa. Especificamente, quando o movimento parte do sinalizante. Já a forma bimanual usada para expressar sujeito plural só ocorre quando este se refere a segundas ou terceiras pessoas. Em outras palavras, quando o movimento vai na direção do sinalizante que, nesse caso, é o complemento do verbo. 
Essa uniformidade na leitura das formas bimanuais dos verbos direcionais que sempre corresponde a uma pluralidade de argumentos não é observada, no entanto, com os verbos não direcionais. Com estes, atestamos não apenas casos em que a forma de duas mãos se vincula à expressão de pluralidade de argumentos, mas também casos em que ela se associa à expressão de pluralidade de eventos e intensidade.

Um exemplo de verbo não direcional cuja forma bimanual expressa pluralidade de argumento é COLAR (na prova) (figura 4). No exemplo de uso analisado neste trabalho, observa-se a sinalizadora empregar sua forma monomanual, realizada com os dedos médio e polegar se tocando pelas pontas enquanto os outros se mantêm distendidos e separados, quando faz referência a um único aluno colando e sua forma bimanual quando diz que todos da sala estavam colando.

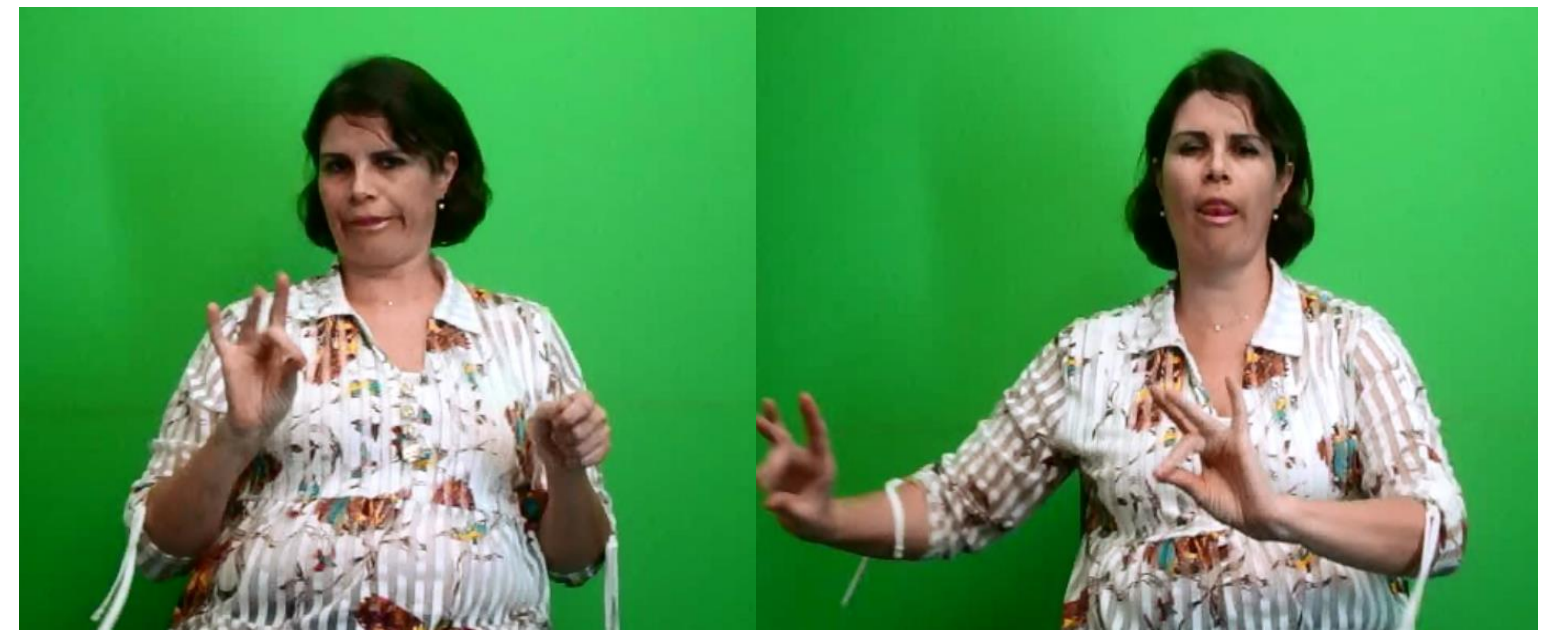

Um(a) aluno(a) estava colando. ${ }^{15}$

Todos os alunos estavam colando.

Figura 4. COLAR (na prova)

Já como exemplo de verbo não direcional cuja forma bimanual se vincula à expressão de pluralidade de eventos, podemos citar APRENDER (figura 5), produzido por meio de um movimento de fechar a mão em frente à testa. No exemplo de uso analisado, a sinalizadora emprega a forma monomanual quando faz referência a um evento de aprender e a forma bimanual quando se refere a um processo que se repete no tempo (em suas palavras, ao longo de uma semana).

15 A mão não dominante aparece nesse caso por conta de um processo fonológico denominado perseveração, que consiste na manutenção de parte do sinal anterior (XAVIER, 2014). 


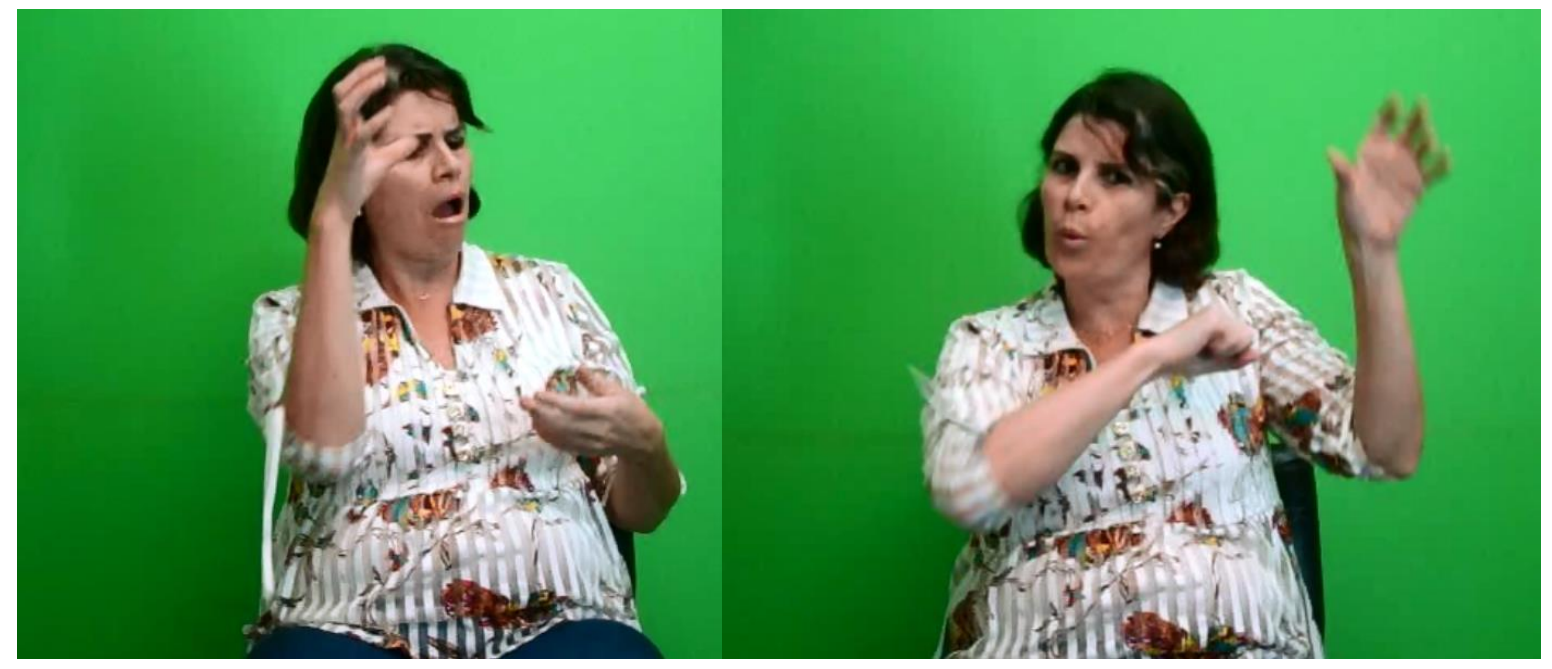

Aprendi sobre a psicanálise.

Na segunda aprendi sobre passe, na terça....fui aprendendo ao longo da semana.

Figura 5. APRENDER

Por fim, como exemplo de verbo não direcional expressando, por meio de sua forma bimanual, intensidade, podemos citar RIR (figura 6), realizado com a mão exibindo o polegar distendido, o indicador em gancho e os demais dedos fechados e girando pelo pulso em frente à boca. Como explica a sinalizadora, no exemplo que analisamos, RIR é produzido com uma mão quando faz referência à ação de rir em seu grau típico e com duas quando se refere em seu grau de intensidade elevado.

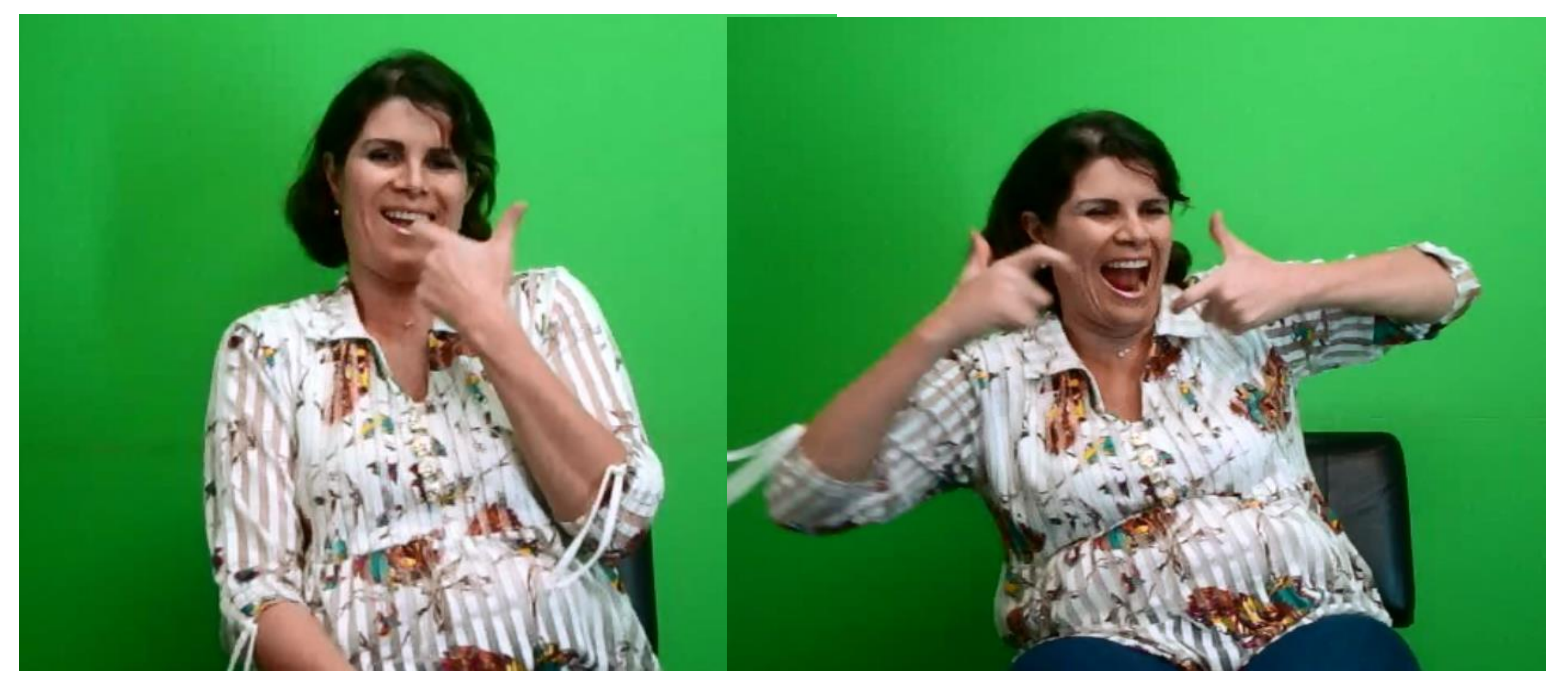

Rir (normal).

Rir muito.

Figura 6. RIR

Vale ressaltar que, além do acréscimo de um articulador manual, as formas bimanuais também apresentam, em relação à sua forma monomanual correspondente, mudanças nas características do movimento e das expressões faciais. COLAR (na prova), por exemplo, na forma bimanual exibe movimento circular e simultâneo das mãos, ao passo que em sua forma monomanual apresenta apenas movimento de tocar 
dos dedos polegar e médio. Trabalhos futuros devem explorar as modificações em outros aspectos articulatórios dos sinais e verificar suas contribuições semânticas para as formas duplicadas.

\section{Considerações Finais e Próximos Passos}

Neste artigo, argumentamos que a duplicação de mãos em verbos expressa pluracionalidade em libras. Dessa forma, abarcamos dentro de uma mesma operação as leituras de plural de participantes, de plural de eventos e de intensidade dos dados analisados.

Como vimos, em algumas línguas, traços semânticos podem determinar o tipo de leitura produzida pelo marcador pluracional. Em checheno, por exemplo, a telicidade é o traço determinante para a seleção de leituras dos verbos pluracionalizados. $\mathrm{Na}$ libras, porém, defendemos que um traço que estabelece relação com o efeito semântico da duplicação de mãos é a direcionalidade. Verbos direcionais apresentam leitura de plural de argumentos quando são pluracionalizados, enquanto que verbos não direcionais podem expressar plural de argumentos, plural de eventos e intensidade.

Os próximos passos da pesquisa serão no sentido de investigar algum critério que possa auxiliar na separação das leituras associadas aos verbos bimanuais não direcionais. Além disso, exploraremos as modificações em outros aspectos articulatórios dos sinais (sobretudo movimento e expressões faciais), a fim de verificar suas contribuições semânticas para as formas duplicadas. Dessa forma, a pesquisa dos efeitos semânticos da pluracionalidade poderá auxiliar na maior compreensão acerca do significado dos verbos da libras e contribuir para o entendimento da semântica da língua como um todo, um campo ainda muito pouco explorado.

\section{REFERÊNCIAS}

CUSIC, D. D. Verbal Plurality and Aspect. 1981. 388 f. Tese (Doutorado em Linguística) - Stanford University, Stanford, Estados Unidos.

FELIPE DE SOUZA, T. A. A relação sintático-semântica dos verbos e seus argumentos na Língua Brasileira de Sinais (libras). 1998. 298 f. Tese (Doutorado em Linguística) Centro de Letras e Artes, Universidade Federal do Rio de Janeiro, Rio de Janeiro.

FINAU, R. A. Os Sinais de Tempo e Aspecto na libras. 2004. 238 f. Tese (Doutorado em Linguística) - Universidade Federal do Paraná, Curitiba.

HENRY, J. The Kaingang language. International Journal of American Linguistics, n. 14.3, p. 194-213, 1948.

KEY, H. Stem construction and affixation of Sierra Nahuat verbs. International Journal of American Linguistics, n.26, p. 130-145, 1960.

MALAIA, E.; WILBUR, R. B. Telicity expression in the visual modality. In: DEMONDE, V.; MCNALLY, L. (eds.). Telicity, Change, and State. Nova Iorque: Oxford University Press, 2012. p. 122-138.

MOREIRA, R. L. Uma Descrição da Dêixis de Pessoa na Língua de Sinais Brasileira (LSB): Pronomes Pessoais e Verbos Indicadores. 2007. 150 f. Dissertação (Mestrado em 
Linguística) - Departamento de Linguística, Universidade de São Paulo, São Paulo.

LASERSOHN, P. Plurality, Conjunction, and Events. Boston: Kluwer Academic Publishers, 1995. $304 \mathrm{p}$.

QUADROS, R. M.; KARNOPP, L. Lingua de sinais brasileira: estudos lingüísticos. Porto Alegre: ARTMED, 2004. 221 p.

RODERO-TAKAHIRA, A. G. Compostos na língua de sinais brasileira. 2015. $161 \mathrm{f}$. Tese (Doutorado em Linguística) - Faculdade de Filosofia, Letras e Ciências Humanas, Universidade de São Paulo, São Paulo.

ROSE, F. Reduplication in Tupi-Guarani languages: going into opposite directions. Studies on Reduplication, Mouton de Gruyter. 2005. p. 351-368.

SANCHEZ-MENDES, L.; MÜLLER, A. The Expression of Quantification in Karitiana: Pluractionality and Quantifiers. In: DEAL, A. R. (ed.). UMOP 35: Proceedings of the 4th Conference of semantics of under-represented languages in the Americas. Amherst: BookSurge Publishing, 2007. p. 247-257.

STRICKLAND, B.; GERACI, C.; CHEMLA, E.; SCHLENKER, P.; KELEPIR, M.; PFAU, R. Event representations constrain the structure of language: Sign language as a window into universally accessible linguistic biases. PNAS, n. 112 (19), p. 5968-5973, 2015 .

VENDLER, Z. Verbs and times. The Philosophical Review, n. 66.2, p. 143-160, 1957.

WILBUR, R. B. Representation of telicity in ASL. Chicago Linguistic Society, n. 39(1), p. 354-368, 2003.

XAVIER, A. N. Uma ou duas? Eis a questão! Um estudo do parâmetro número de mãos na produção de sinais da Língua Brasileira de Sinais (libras). 2014. 158 f. Tese (Doutorado em Linguística) - Instituto de Estudos da Linguagem, Universidade Estadual de Campinas, Campinas.

YU, A. Pluractionality in Chechen. Natural Language Semantics, n. 11, p. 289-321, 2003.

Recebido em: 18/09/2015

Aprovado em: 29/01/2016 